\title{
Editorial
}

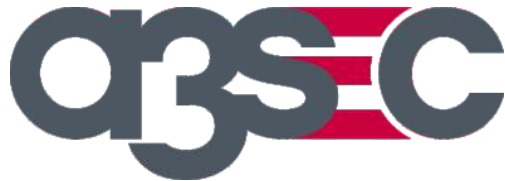

Hacemos del DATO el acelerador de su negocio España - Colombia - México - U.S.A.

\section{Tecnología y \\ equidad social}

DOI: 10.29236/sistemas.n157a1

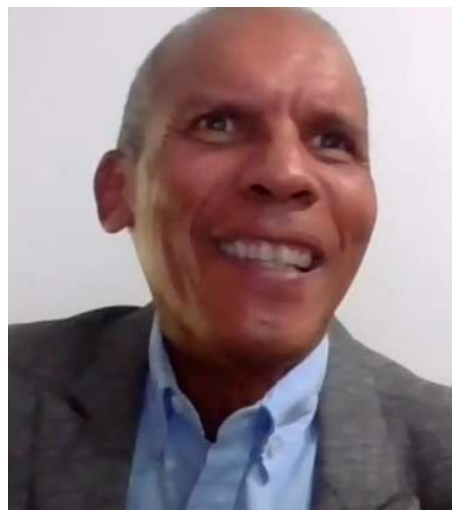

Emir Hernando Pernet C., DBA, MBA, MCS

Antes de referirme a los diferentes artículos de esta edición, considero pertinente aclarar la diferencia entre los términos igualdad y equidad, con la ayuda de las imágenes 1 y 2.

La tecnología es uno de los instrumentos con los que cuenta el Estado para garantizar un trato equitativo a la sociedad. "Hoy sabemos que la conectividad es equidad...", declaró la ministra de las Tecnologías de Información y Comunicaciones (TIC), Karen Abudinen, el pasado 9 de septiembre de $2020^{1}$. Afirmación que enfatiza Gloria Alonso, actual Embajadora Alterna de la Embajada de Colombia ante

https://www.mintic.gov.co/portal/inicio/Sala-de-Prensa/ Noticias/150794:Ministra-Karen-Abudinen-reveloelcumplimiento-del-85-de-los-compromisos-dedesarrollo-en-materia-TIC-pactados-con-la-OCDE 
Imagen 1

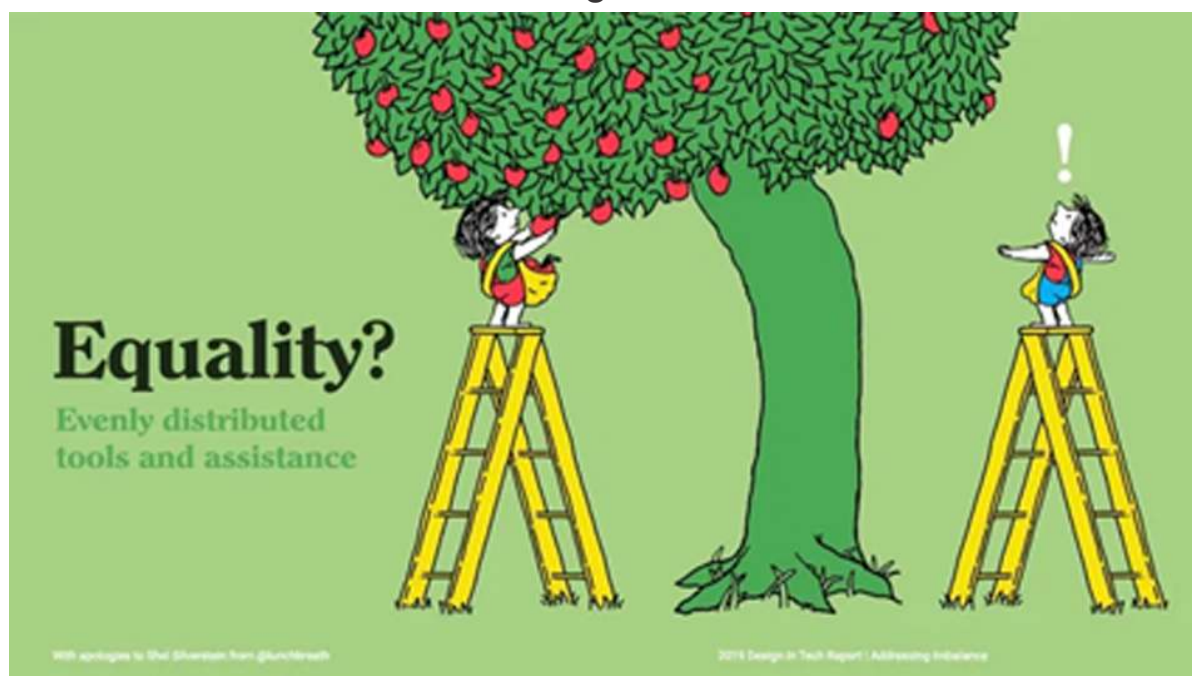

Fuente: https://designintech.report/2019/03/11/\%F0\%9F\%93\%B1design-intech-report-2019-section-6-addressing-imbalance/

La igualdad se define como la forma de tratar a cada individuo, independientemente de sus necesidades y requisitos (Harerimana, 2019).

Imagen 2

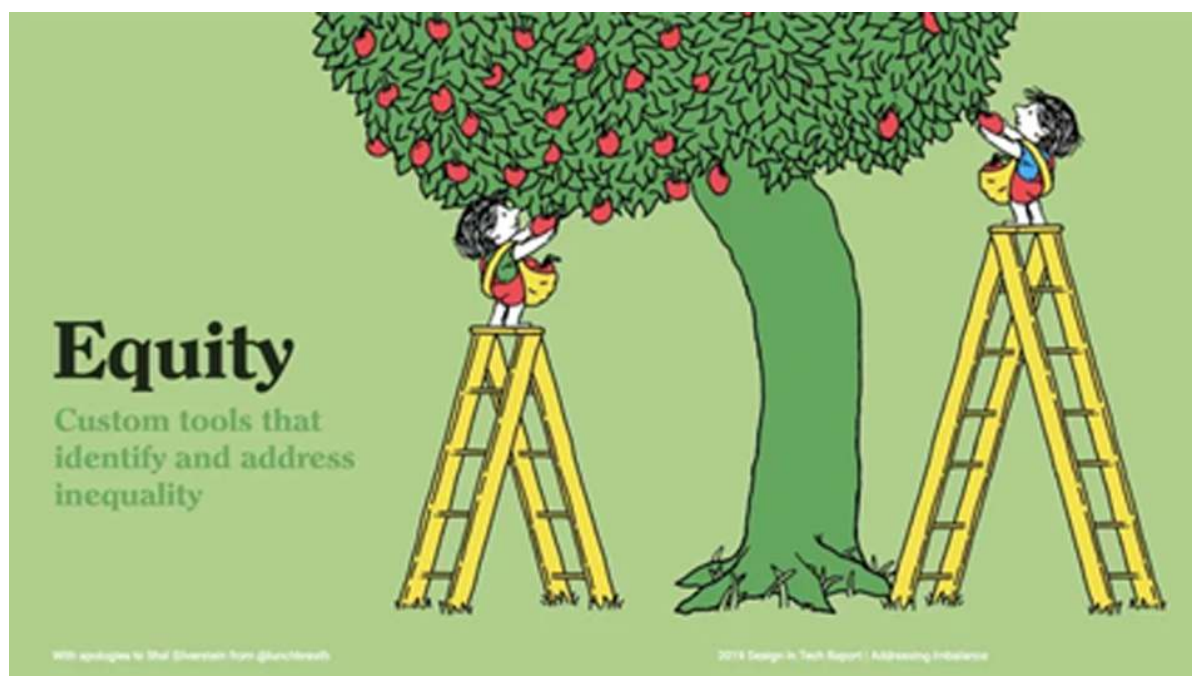

Fuente: https://designintech.report/2019/03/11/\%F0\%9F\%93\%B1design-intech-report-2019-section-6-addressing-imbalance/

La equidad se define como la forma de tratar a las personas de manera justa, en función de sus necesidades y requisitos (Harerimana, 2019). 
la Organización para la Cooperación y el Desarrollo Económicos OCDE-, cuando afirma que "la verdadera equidad es garantizar los derechos de los colombianos"', y señala que la primera acarrea una transformación social total.

La perspectiva del Gobierno con referencia al uso la tecnología como instrumento para garantizar los derechos de los colombianos se puede leer en tres secciones de esta revista: en la entrevista realizada al Asesor para Asuntos Económicos y Transformación Digital en la Presidencia de la República, Víctor Manuel Muñoz; así mismo, en la investigación sobre el avance del "Pacto por la ciencia, la tecnología y la innovación" y del "Pacto por la transformación digital de Colombia" dentro del Plan Nacional de Desarrollo 2018 - 2022, denominado "Pacto por Colombia, pacto por la equidad" y en "Cara y Sello", texto que describe el foro realizado en este número.

En dicho encuentro los invitados Martha Gaitán, Sandra Hernández, Manuel Dávila, Rafael González y Lenin Ortiz expusieron las expectativas sobre el rol del Estado en la promoción de soluciones tecnológicas orientadas a apoyar el fortalecimiento de los derechos fundamentales de los colombianos. De

https://www.larepublica.co/analisis/gloria-alonso2793634/equidad-para-avanzar-en-la-transformacionsocial2834148 igual forma, los participantes tuvieron la oportunidad de describir los aportes a la equidad social de los sectores que ellos representan.

En su columna, Mónica María López Sánchez muestra que un cambio cultural gestado desde la persona y cimentado en la ética y el respeto por la condición humana, es la clave para que las soluciones tecnológicas generen un verdadero bienestar para la humanidad. La invitada López advierte que la transformación digital no puede lograr los resultados esperados, a menos que venga acompañada de una transformación cultural que genere la apropiación y adopción de las nuevas tecnologías por parte del ser humano.

En su artículo "Ciencias satelitales e inclusión social", Manuel Dávila Sguerra presenta casos reales y prácticos sobre el uso de "Satélites Sociales". Estas soluciones tecnológicas concebidas bajo el concepto de Ingeniería Humanitaria, no solo buscan el bienestar y el desarrollo de las comunidades más desfavorecidas, de manera participativa, sino que vinculan a las comunidades con las teorías científicas y los desarrollos tecnológicos.

Finalmente, Jeimy J. Cano Martínez describe su teoría que califica como un impuesto progresivo a la inseguridad digital, basado en el hecho de que la misma, representada en los ciberataques, mina la confianza digital de los consumi- 
dores y genera tal incertidumbre, que afecta la dinámica empresarial y la prosperidad económica de las naciones. Considerando la inseguridad digital algo inevitable, el autor presenta dos estrategias para enfrentarla: la evasión y la elusión.

¡Bienvenidos a la consulta de estos contenidos!

Emir Hernando Pernet Carrillo, DBA, PMP. Asesor Senior del Departamento de Sistemas de Información del Banco de la República, Colombia. Ingeniero de Sistemas y Computación de la Universidad de los Andes, Colombia, y MBA de ese mismo centro educativo. Master of Computer Science de Arizona State University, USA. Doctor of Business Administration de Newport University, USA. Project Management Professional del Project Management Institute. Editor técnico para esta edición de la revista Sistemas de la Asociación Colombiana de Ingenieros de Sistemas (Acis). 